\title{
P97 Inhibitor CB-5083
}

National Cancer Institute

\section{Source}

National Cancer Institute. p97 Inhibitor CB-5083. NCI Thesaurus. Code C118287.

An orally bioavailable inhibitor of valosin-containing protein (VCP) p97, with potential antineoplastic activity. Upon oral administration, CB-5083 specifically binds to and inhibits the activity of p97. This prevents ubiquitin-dependent protein degradation and causes cellular accumulation of poly-ubiquitinated proteins. The inhibition of endoplasmic reticulum (ER)-associated protein degradation activates the ER-dependent stress response pathway, and leads to both an induction of apoptosis and inhibition of cell proliferation in susceptible tumor cells. p97, a type II AAA ATPase, plays a key role in cellular protein homeostasis. Its overexpression in many tumor cell types is associated with increased tumor cell proliferation and survival. 